\title{
COMPARISON OF HAEMODYNAMICS AND BLOOD LOSS IN URETHROPLASTY SURGERIES DONE UNDER GENERAL ANAESTHESIA WITH AND WITHOUT CAUDAL BLOCK IN CHILDREN AGED BETWEEN 2-5 YRS
}

\author{
Aavula Muralidhar1, K. Radha Ramana Murthy²
}

${ }^{1}$ Assistant Professor, Department of Anaesthesiology, Niloufer Hospital, Osmania Medical College, Hyderabad, Telangana State. ${ }^{2}$ Professor, Department of Anaesthesiology, Niloufer Hospital, Osmania Medical College, Hyderabad, Telangana State.

\section{ABSTRACT}

Urethroplasty surgery is a painful procedure demanding high doses of analgesics, which may be associated with adverse effects and associated with significant blood loss. Caudal blockade provides good analgesia and hemodynamic stability and is probably a useful supplement in these surgeries.

\section{OBJECTIVES}

To compare the heart rate, blood pressure response to surgical stimuli and the incidence of blood transfusion rate postoperatively between 2 groups - A) General Anaesthesia only. B) General Anaesthesia with caudal block.

\section{SETTINGS AND DESIGN}

Study was conducted in 100 children, randomly divided into two groups A and B. Only ASA grade 1 patients aged 2-5yrs. undergoing urethroplasty for hypospadias were included.

\section{MATERIALS AND METHODS}

$1 \mathrm{ml} / \mathrm{kg}$ of $0.125 \%$ bupivacaine was used for caudal blockade in group B (GA+CAUDAL) and compared with group A (Only GA). Heart rate and blood pressure were recorded for every $5 \mathrm{~min}$. Blood loss and requirement of blood transfusions were recorded at the end of the surgery.

\section{RESULTS}

There were statistically significant haemodynamic changes and blood transfusion requirement during surgery in group A. In Group B haemodynamic parameters were stable ( $P$ value 0 ) and blood transfusion requirement was also less ( $p$ value 0.00054 ) $(\mathrm{P}<0.01)$.

\section{CONCLUSION}

Caudal blockade when supplemented with general anaesthesia reduces blood loss, decreases requirement for blood transfusion and maintains haemodynamic stability.

\section{KEYWORDS}

Caudal Blockade, Heart Rate, Blood Loss, Blood Transfusion.

HOW TO CITE THIS ARTICLE: Aavula Muralidhar, K. Radha Ramana Murthy. "Comparison of Haemodynamics and Blood Loss in Urethroplasty Surgeries Done Under General Anaesthesia with and without Caudal Block in Children Aged Between 2-5 Yrs." Journal of Evolution of Medical and Dental Sciences 2015; Vol. 4, Issue 99, December 10; Page: 16417-16421, DOI: $10.14260 /$ jemds/2015/2433

\section{CAUDAL BLOCK}

It is a technique of epidural blockade commonly performed in children, wherein drug is deposited in caudal epidural space through the sacrococcygeal membrane. Caudal anesthesia was first described at the turn of last century by two French physicians, Fernand Cathelin and Jean-Anthanase Sicard. The technique predated the lumbar approach to epidural block by several years.

Indications and Contraindications.(1)

\section{INDICATIONS}

Any surgery performed on lower abdomen and lower extremities.

\section{Contraindications - Relative \\ 1. Pilonidal cyst. \\ 2. Hydrocephalus. \\ 3. Intracranial tumors.}

Financial or Other, Competing Interest: None

Submission 25-11-2015, Peer Review 26-11-2015,

Acceptance 04-12-2015, Published 09-12-2015.

Corresponding Author:

Dr. Aavula Muralidhar

6-4-584, MIG-235, Phase 4, Vanasthalipuram,

Hyderabad-70, Telangana State, India.

E-mail:aavulaklmn@yahoo.co.in

DOI:10.14260/jemds/2015/2433

\section{Absolute}

1. True meningomyelocele of the sacrum or meningitis.

2. Medicolegal implications-progressive degenerative neuropathy.

Anatomy

1. Caudal space is the result of non-fusion of 5th sacral vertebral arch, which forms sacral hiatus.

2. Landmarks around sacral hiatus are sacral cornua, coccyx and posterior superior iliac spines.

3. Line joining the two posterior superior iliac spines would be the base of the equilateral triangle whose apex is at the location of sacral hiatus.

4. Caudal space lies underneath the sacrococcygeal ligament

5. After 7 yrs. of age the child's caudal space becomes more angulated and is difficult to enter and also formation of presacral fat pad in puberty adds to difficulty in placing the block.

6. Dural sac extends up to S3 in neonates, the possibility of entering the dural sac in this age group should be considered.

Physiology and Characteristics of the Blockade. $(2,3,4)$ Caudal epidural block results in sensory and motor block of the sacral roots and limited autonomic block. 
The sacral contribution of the parasympathetic nervous system is blocked, causing loss of visceromotor function of the bladder and intestines distal to the colonic splenic flexure. Sympathetic block, though limited compared with lumbar or thoracic epidural block, does occur. The sympathetic outflow from the spinal cord ends at the L2 level, and therefore caudal block should not routinely result in peripheral vasodilatation of the lower extremities to the degree witnessed with lumbar epidural blockade. Caudal blockade decreases stress hormone response to surgery, therefore fasted infants are prone to develop hypoglycemia. So dextrose containing solutions should be administered; $0.125 \%$ and $0.175 \%$ of bupivacaine have been shown to be appropriate concentrations which produce adequate analgesia without postoperative motor blockade, whereas $0.25 \%$ bupivacaine may occasionally produce a motor blockade in the lower extremities.

\section{TECHNIQUE}

1. Child should be in lateral position, flex the hips with the dependent leg less flexed than the top leg (Simms position).

2. Near the cephalad margin of the gluteal crease, sacral cornua should be felt and sacral hiatus is present immediately inferior and in midline.

3. After sterile preparation and draping, sacral hiatus identified with non-dominant hand and needle is placed into the skin at a 45-degree angle or less and advanced aiming cephalad, resistance is felt when sacrococcygeal ligament is passed.

4. After negative aspiration for blood and CSF, local anesthetic is injected. Make sure the drug is not being injected subcutaneously, although air has been used to check for crepitus after injection. This practice is not recommended for the risk of air embolism.

\section{Duration of Caudal Analgesia.(5)}

The duration of effective analgesia is considerably longer than one would expect based on the usual length of action of the local anesthetic alone. A study that compared $0.25 \%$ bupivacaine with and without epinephrine found that the addition of epinephrine markedly prolonged the analgesia and that prolonged duration of analgesia was correlated with both younger age and lower surgical site (Penoscrotal versus inguinal) (Warner et al. 1987). Duration of analgesia ranged from as short as 5 hours (Inguinal surgery, older than 11 years) to as long as 23 hours (Penoscrotal operation, 1 to 5 years old) as judged by the time to first requirement for supplemental analgesia.

BUPIVACAINE: It is a racemic mixture of equimolar amounts of enantiomers $\mathrm{R}(+)$ \& $\mathrm{S}(-)$ bupivacaine.

1. It is an amide local anaesthetic.

2. Toxicity-occurs when doses $>2 \mathrm{mg} / \mathrm{kg}$ are used.

In children toxicity occurs at serum concentrations of $2 \mathrm{mcg} / \mathrm{ml}$, whereas in adults at $4 \mathrm{mcg} / \mathrm{ml}$.

Children may be at increased risk for toxicity because of their relatively increased cardiac output and increased systemic uptake of the agent-manifestations of toxicitydysrhythmias with evidence of high degree of conduction block, widening of QRS, torsades de pointes, ventricular tachycardia related to re-entry phenomenon, decreased myocardial contractility.

\section{Management of Toxicity}

1. Oxygenation and ventilation done to decrease rise in $\mathrm{PaCO} 2$, because increased $\mathrm{PaCO} 2$ displaces local anaesthetic from its protein binding site.

2. Cardiovascular resuscitation.
3. Intralipid $20 \%$ - initial dose $-1-1.5 \mathrm{ml} / \mathrm{kg}$ over $1 \mathrm{~min}$, then repeat the same dose every 3-5 min during resuscitation up to a total of $3 \mathrm{ml} / \mathrm{kg}$. On evidence of recovery, start infusion at $0.25-0.50 \mathrm{ml} / \mathrm{kg} / \mathrm{min}$. This works because bupivacaine along with other long acting local anaesthetics like ropivacaine and levobupivacaine is highly soluble in lipid emulsion.

\section{Levobupivacaine}

Levobupivacaine is the $S(-)$ enantiomer of bupivacaine and is less toxic to the CNS or heart than is racemic bupivacaine.

\section{Ropivacaine}

Ropivacaine has shown promise in pediatric patients with the onset times similar to bupivacaine and durations of actions that are similar or perhaps slightly longer than bupivacaine.

Ropivacaine has less risk of CNS and cardiac toxicity than bupivacaine. In fact, inadvertent intravenous ropivacaine in a 1-year-old child failed to produce neurotoxic or cardiotoxic signs or symptoms.

\section{Lignocaine}

It is an amide local anaesthetic with faster onset of action (5$10 \mathrm{~min}$ ). Its duration of action is for only $45-60 \mathrm{~min}$.

For caudal blockade, $1 \%$ to $1.5 \%$ concentrations are used.

\begin{tabular}{|c|c|}
\hline $\begin{array}{c}\text { Plasma Lidocaine } \\
\text { Concentration }(\boldsymbol{\mu g} / \mathbf{m L})\end{array}$ & Effect \\
\hline $1-5$ & Analgesia \\
\hline $5-10$ & Circumoral numbness \\
\hline & Tinnitus \\
\hline & $\begin{array}{c}\text { Skeletal muscle } \\
\text { twitching }\end{array}$ \\
\hline & Systemic hypotension \\
\hline & Myocardial depression \\
\hline $10-15$ & Seizures \\
\hline $15-25$ & Unconsciousness \\
\hline & Apnea \\
\hline$>25$ & Coma \\
\hline & $\begin{array}{c}\text { Cardiovascular } \\
\text { depression }\end{array}$ \\
\hline Dose-Dependent Effects of Lidocaine \\
\hline
\end{tabular}

Drug dosage as suggested by Armitage.(6)

1. $0.5 \mathrm{ml} / \mathrm{kg}$ - all sacral dermatomes are blocked

2. $1 \mathrm{ml} / \mathrm{kg}$ - all sacral and lumbar dermatomes blocked.

3. $1.25 \mathrm{ml} / \mathrm{kg}$ - blockade is up to midthoracic.

Bupivacaine, ropivacaine and levo-bupivacaine can be used for bupivacaine and ropivacaine $0.25 \%$ concentrations are used. ${ }^{*}$ Greater concentration and large doses are reserved for levobupivacaine.

\begin{tabular}{|c|c|c|c|}
\hline $\begin{array}{c}\text { Local } \\
\text { Anesthetic }\end{array}$ & $\begin{array}{c}\text { Single } \\
\text { Dose } \\
\text { (mg/kg) }\end{array}$ & $\begin{array}{c}\text { Continuous } \\
\text { Infusion } \\
\text { Rate } \\
\text { (mg/kg per } \\
\text { hr.) }\end{array}$ & $\begin{array}{c}\text { Continuous } \\
\text { Infusion Rate } \\
\text { in Infants }<6 \\
\text { Months of } \\
\text { Age }{ }^{[\neq]} \\
\text {(mg/kg per } \\
\text { hr.) }\end{array}$ \\
\hline Bupivacaine & 3 & 0.4 to 0.5 & 0.2 to 0.25 \\
\hline Levobupivacaine & $\left.3^{*}\right]$ & 0.4 to 0.5 & 0.2 to 0.25 \\
\hline Ropivacaine & $\left.3^{*}\right]$ & 0.4 to 0.5 & 0.2 to 0.25 \\
\hline Lidocaine & 5 & 1.6 & 0.8 \\
\hline $\begin{array}{c}\text { Lidocaine with } \\
\text { epinephrine[†] }\end{array}$ & 7 & NA & NA \\
\hline \multicolumn{4}{|c|}{ Maximal Allowable Dosing Guidelines } \\
of Local Anesthetics.(7) \\
\hline
\end{tabular}

Modified from Berde, 1992. NA, Not Applicable. 


\begin{tabular}{|c|l|}
\hline$*$ & $\begin{array}{l}\text { Maximal allowable dose may be up to } 4 \mathrm{mg} / \mathrm{kg} \\
\text { (under investigation). }\end{array}$ \\
\hline$\dagger$ & $\begin{array}{l}\text { Epinephrine added to local anesthetic at } 5 \mathrm{mcg} / \mathrm{mL} \\
\text { or } 1: 200,000 .\end{array}$ \\
\hline$\ddagger$ & $\begin{array}{l}\text { Rate should be reduced by additional } 30 \% \text { after } \\
48 \text { hours in infants. }\end{array}$ \\
\hline
\end{tabular}

\section{COMPLICATIONS OF CAUDAL BLOCKADE. 8}

1. Complications due to local anesthetic.

2. Accidental injection into intravascular space resulting in local-anesthetic toxicity.

3. Injection into sacral-marrow.

4. Injection into subarachnoid space.

5. Hypotension usually does not occur in children $<5 y$ rs of age because of,

a) Immature sympathetic nervous system.

b) Less pooling of blood in lower extremities because of less proportion of lower extremities to overall body size.

6. Urinary-retention.

HAEMODYNAMIC RESPONSE TO CAUDAL ANALGESIA.(9,10)

1. Cardiac output does not change.

2. Pulmonary artery resistance is increased and it is not recommended in children with pulmonary hypertension.

3. Caudal anesthesia does not affect HR and MAP.

Doppler studies have shown minimal alterations in blood pressure and $\mathrm{CO}$ in young children because children may have a different baseline sympathetic tone compared with adults, who typically respond to blockade with hypotension. In addition, children may have less venous pooling and smaller lower extremity-to-body surface area ratios.

If a normal circulating blood volume is present fluid loading, which is normally done in adults is unnecessary in children. The effects of caudal extradural analgesia on pulmonary and systemic arterial pressure have been examined in children.(2) Insignificant change in pulmonary arterial pressure and aortic pressure in children with normal cardiac function was noted. Aortic pressure did decrease significantly in children with cardiac disease. In addition if pulmonary hypertension was present before block, pulmonary artery pressure increased significantly.

There is a profound interaction between cardiovascular stability and pain systems. Caudal anesthesia abolishes pain and hence produces cardiovascular stability.

\section{STUDY}

\section{INTRODUCTION}

Urethroplasty surgery is associated with significant blood loss and is a painful procedure demanding high doses of analgesics, which may be associated with adverse effects. Caudal blockade provides good analgesia and hemodynamic stability and is a useful supplement in these surgeries.

\section{AIM OF THE STUDY}

Comparison of haemodynamics and blood transfusion requirements in urethroplasty surgeries done under general anesthesia with or without caudal blockade in children aged 25 yrs.

\section{OBJECTIVES}

1. To compare the heart rate response to surgical stimuli.

2. To compare the blood pressure response to surgical stimuli.

3. To compare blood transfusion requirements postoperatively.

\section{MATERIALS AND METHODS}

The study was conducted at Niloufer Hospital in 100 pediatrics patients undergoing urethroplasty stage 2 with tunica vaginalis flap - Tourniquet not used for hypospadias. All the surgeries done by the same surgeon.

They all belong to ASA - grade 1 physical status in the age group of 2-5yrs. All the patients underwent following investigations complete blood picture, coagulation profile, urea, creatinine, other surgical profile.

Premedication - Inj. Glycopyrrolate $4 \mathrm{mcg} / \mathrm{kg}$, Ondansetron $\quad 0.1 \mathrm{mg} / \mathrm{kg}$, Fentanyl $2 \mathrm{mcg} / \mathrm{kg}$ given intravenously.

Induced and intubated with Inj. Propofol $2 \mathrm{mg} / \mathrm{kg}$, Inj. Vecuronium $0.1 \mathrm{mg} / \mathrm{kg}$.

Caudal blockade given with $1 \mathrm{ml} / \mathrm{kg}$ of $0.125 \%$ Bupivacaine.

The patients were randomly allocated into two groups (Having 50 in each group).

GROUP A - Comprising of 50 patients who received only General Anesthesia.

GROUP B - Comprising of 50 patients who received caudal anesthesia in addition to General anesthesia.

\section{The parameters recorded were;}

1. Heart rate (recorded every $5 \mathrm{~min}$ ).

2. Blood pressure (recorded every $5 \mathrm{~min}$ ).

3. Blood loss -measured by weighing mops soaked with blood.

4. Blood transfusion requirements -after consideration of allowable blood loss.

Maximum allowable blood loss =

(Starting haematocrit - target haematocrit)/Starting haematocrit X Estimated blood volume $(70-75 \mathrm{ml} / \mathrm{kg})$.

Amount to transfuse $=$ Target haemoglobin - Current haemoglobin X 4 X weight $(\mathrm{kg})$.

\section{RESULTS}

There were statistically significant haemodynamic (Blood pressure and heart rate) alterations and blood transfusion requirements between two groups with $p$ value $<0.05$. The haemodynamic parameters were stable in group B who received caudal blockade and blood transfusion requirement was also less in this group.

\section{Table 1 and Diagram 1}

Shows heart rate changes in both groups. Heart rate was very much stable in GA with caudal block group patients. There was no change in HR in 29 patients out of 50 and minimal change in remaining patients in comparison with the other group who received only General Anesthesia where 32 patients out of 50 showed significant change in heart rate $(>160)$.

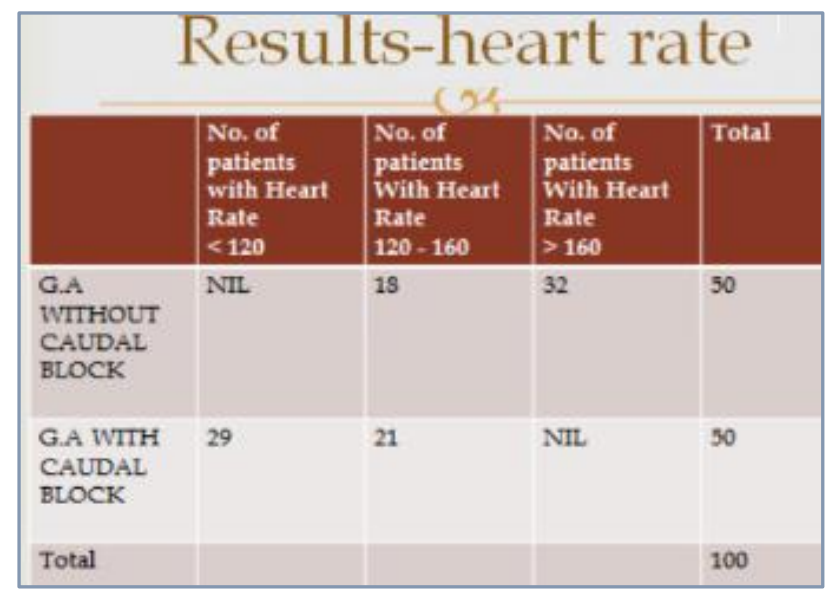

TABLE 1 


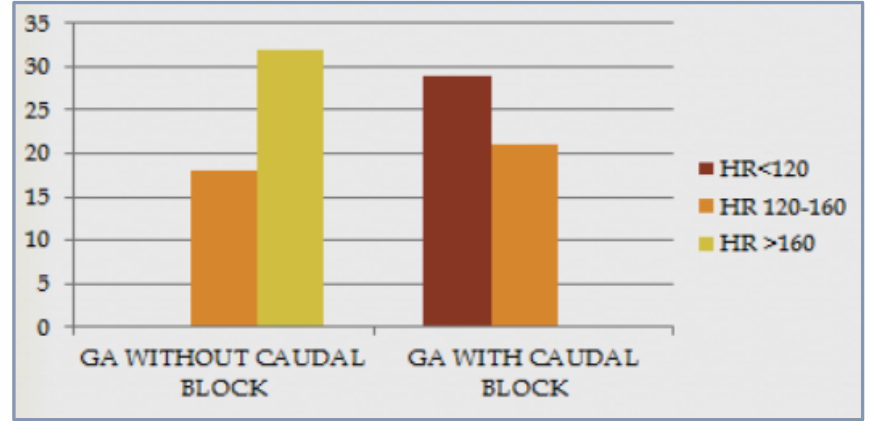

DIAGRAM 1

Table 2 and Diagram 2

Shows blood pressure changes in both groups. Blood pressure was also very much stable in GA with caudal block group, 32 patients out of 50 there was no rise in basic blood pressure, whereas in patients who received only GA there was significant rise $>20 \%$ in basic blood pressure, 37 patients out of 50 .

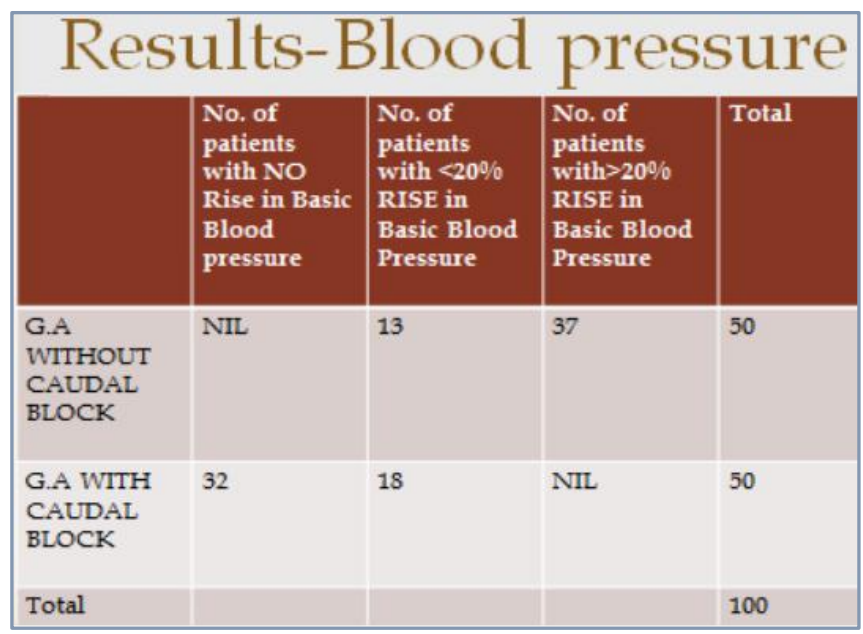

TABLE 2

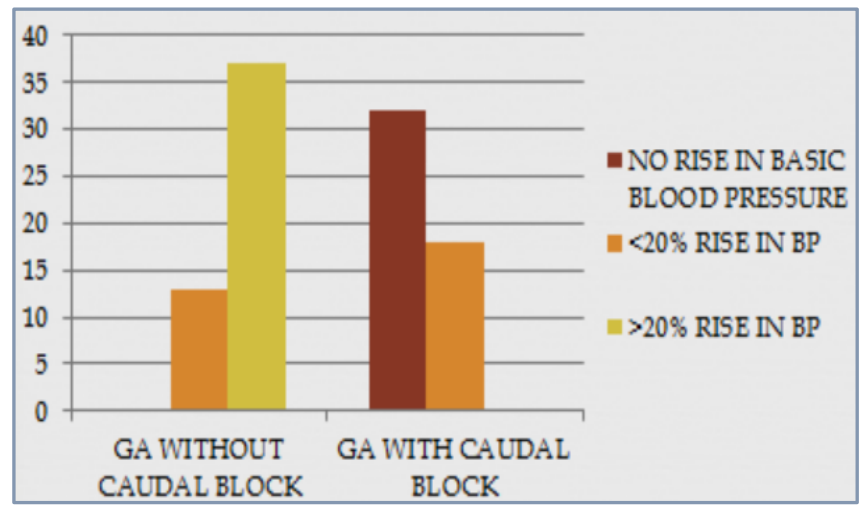

DIAGRAM 2

\section{Table 3 and Diagram 3}

Shows requirement of blood transfusion post-operatively. Requirement of blood transfusion was very less in patients who received GA with Caudal block, only one patient out of 50 whereas in patients who received only GA 12 out of 50 patients received blood transfusion post-operatively.

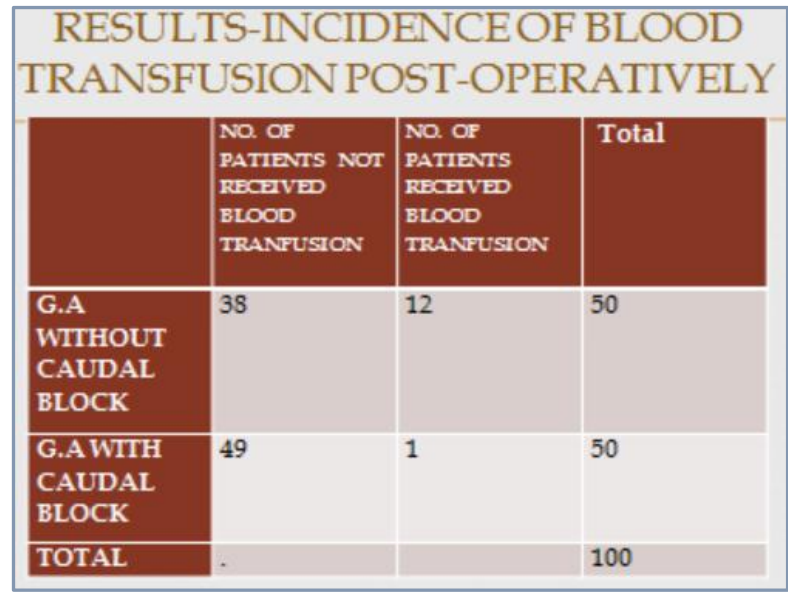

TABLE 3

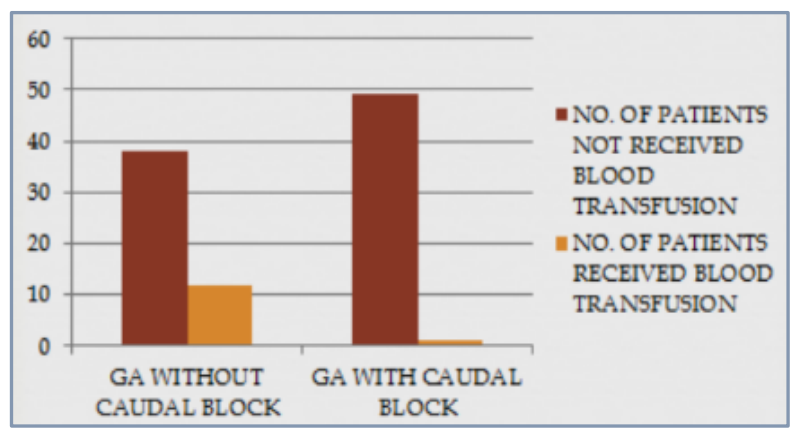

DIAGRAM 3

\section{DISCUSSION}

Caudal anaesthesia provides excellent analgesia, which prevents sympathetic response to surgical stimuli. HAEMODYNAMIC RESPONSE TO CAUDAL ANALGESIA: 1) Cardiac output does not change. 2) Caudal anesthesia does not affect HR (Heart rate) and MAP (Mean arterial pressure). The sympathetic outflow from the spinal cord ends at the L2 level and therefore caudal block should not routinely result in peripheral vasodilatation of the lower extremities. Stable haemodynamics and lack of marked peripheral vasodilation decreases blood loss and blood transfusion requirements; $0.125 \%$ bupivacaine is the appropriate concentration, which produce adequate analgesia without postoperative motor blockade.

Dosage as suggested by Armitage

- With $0.5 \mathrm{ml} / \mathrm{kg}$, all sacral dermatomes are blocked.

- With $1.0 \mathrm{ml} / \mathrm{kg}$, all sacral and lumbar dermatomes are blocked.

- With $1.25 \mathrm{ml} / \mathrm{kg}$, the upper limit of anesthesia is at least midthoracic.

In patients with GA without caudal block, heart rate is increased in response to surgical stimuli with resultant increase in cardiac output leading to increase in blood loss and blood transfusion requirements.

\section{CONCLUSIONS}

Caudal blockade when combined with general anaesthesia for urethroplasty results in haemodynamic stability and minimizes blood loss. Caudal blockade also gives very good analgesia intra-operatively and post-operatively and avoids excessive use of opioids and NSAIDS. Continuous caudal blockade by using catheter totally avoids use of both opioids and NSAIDs. 


\section{REFERENCES}

1. Aprodu GS, Munteanu V, Filciu G, Goţia DG (2008) caudal anesthesia in pediatric surgery. Rev Med Chir Soc Med Nat Iasi 112:142-147.

2. www.frca.co.uk- anesthesia for hypospadias repair.

3. Journal of urology www.reaserchgate.net.

4. Silvani P, Camporesi A, Agostino MR, Salvo I. Caudal anesthesia in pediatrics: An update.minerva Anestesiol 2006;72:453-9.

5. Fisher QA, McComiskey CM, Hill JL, Spurrier EA, Voigt RE, Savarese AM, Beaver BL, Boltz MG (1993). Postoperative voiding interval and duration of analgesia following peripheral or caudal nerve blocks in children. Anesth Analg 76:173-177.
6. Miller's Anesthesia. $7^{\text {th }}$ ed 2010. p. 2519-57.

7. Smith anaesthesia for paediatrics ( $7^{\text {th }}$ edition) p.466-474 \& p.782-784.

8. Oxford Specialist Handbooks in Anaesthesia - Paediatric Anaesthesia. Oxford University press 2007.

9. BNF for Children 2007. BMJ Publishing Group, London.

10. Samuel M, Hampson-Evans D, Cunnington P (2002) Prospective to a randomized double-blind controlled trial to assess efficacy of double caudal analgesia in hypospadias repair. J Pediatric Surg 37:168-174. doi:10.1053/jpsu.2002.30247 